\title{
2 Reconfigurações da nostalgia e do autêntico: memórias, patrimônios e tecnologias
}

Doutor em Ciências Sociais, Professor Associado da FFCLRP-USP e do PPGCI/ECA-USP.

Doutora em História Social, Professora Associada da FFCLRPUSP e do PPGCI/ECA-USP.
Marco Antônio de Almeida ${ }^{1}$

Giulia Crippa $^{2}$
Resumo - O texto reflete acerca das mudanças ocorridas no conceito de memória e nas práticas das instituições relacionadas a ele. Mostra como a sociedade contemporânea possui traços de nostalgia e preocupação com a construção de patrimônios de naturezas distintas e diversas. Destaca o papel que as tecnologias desempenham nesses processos. Propõe uma investigação exploratória a partir de algumas experiências institucionais e de experiências coletivas voluntárias, em alguns museus e na internet.

Palavras-Chave: Cultura; Memória; Patrimônio; Tecnologias; Identidade.
Abstract - This paper reflects on the changes in the concept of memory and practices of the institutions related to it. It shows how contemporary society has traces of nostalgia and concern for the construction of assets of diverse and distinct natures. It highlights the role that technology plays in these processes. It proposes an exploratory research from some institutional experiences and voluntary collective experiences in some museums and on the Internet.

Keywords: Culture; Memory; Patrimony; Technologies; Identity. 


\section{Introdução}

Jorge Luis Borges, em um conto bastante conhecido, "Funes, o memorioso", nos apresenta um personagem singular: Tadeu Isidoro Funes, dotado de uma capacidade de memorização praticamente absoluta. Nada escapa ao seu poder de observação, e nada por ele é esquecido. O narrador do conto pondera, entretanto, que Funes não era propriamente uma figura inteligente, porque pensar envolve esquecer, abstrair diferenças, generalizar, especular sobre o que ainda não possui existência. Ao final do texto, o narrador estarrecido contempla o personagem, um jovem de apenas dezenove anos: "pareceu-me monumental como o bronze, mais antigo que o Egito, anterior às profecias e às pirâmides. Pensei que cada uma de minhas palavras (que cada uma de minhas atitudes) perduraria em sua implacável memória: tolheu-me o temor de multiplicar gestos inúteis.” (BORGES, 2007, p. 108)

$\mathrm{O}$ desalento do narrador diante de tal personagem e de suas capacidades em alguma medida traduz uma atitude bastante semelhante, perpetrada por certos diletantes e profissionais da memória e do patrimônio diante da internet. Afinal não se trata de um vasto receptáculo passível de abrigar toda a memória universal (com pouca inteligência ou discernimento, é certo, assim como Funes)? Caberia, portanto, apenas a resignação ou a complementação da tarefa, construindo catálogos e/ou motores de busca cada vez mais detalhados e sofisticados. Mas será que essa "solução" tecnológica, de fato, se sustenta? Como ficam as relações entre memória e experiência, as tensões entre cópia e original, entre artificial e autêntico?

Bem antes da internet e das tecnologias digitais, Walter Benjamin já havia refletido sobre questões semelhantes em seu famoso ensaio "A obra de arte na era de sua reprodutibilidade técnica".

Uma das maneiras possíveis de se tentar compreender um dos traços da estrutura de percepção inscrita na dinâmica da cultura popular moderna é por meio do par de noções autenticidadesingularidade. A proliferação massiva de cópias constrói a base do desgaste progressivo da noção de autenticidade, que se supõe apoiar-se em um objeto original ou fundador. Diretamente relacionado à noção simbólica de essência, o princípio subjacente à autenticidade consiste no fato de que somente um objeto primário pode comunicar seu significado de forma imaculada e irrevogável, desaparecendo na reprodução do objeto: “A esfera da autenticidade, como um todo, escapa à reprodutibilidade técnica, e naturalmente, não apenas à técnica" (BENJAMIN, 1987, p. 167). Carentes de essência original, as copias são, de imediato, desvalorizadas como imitações superficiais, enquanto o objeto autêntico aumenta seu prestígio graças ao contraste de sua exclusividade.

Verdadeiro fetiche, a autenticidade representa uma época em que a percepção das coisas era mais direta, devido, principalmente, 
à ausência das complicadas dimensões do Capital, com sua elaborada configuração de um falso sistema de equivalências - o valor de troca -, bem como a ausência de um processo de reprodução mecânica, na qual a proliferação de cópias aumenta, sem que seja objetivado, o valor da originalidade. Constituída pela singularidade no tempo e no espaço, a autenticidade resulta escassa e, por conseqüência, antitética ao processo de modernização. Foi isso, em larga medida, que Benjamin quis traduzir em seu conceito de "aura".

Desse modo, não é temerário afirmar que o mundo moderno - em termos de uma cotidianidade marcada pela presença de mercadorias, bens e serviços urbanos - remonta ao século XIX, aquele mesmo no qual Marx afirmava que "tudo que é sólido desmancha no ar". Esse "desmanchar", entendido como a desconstrução dos antigos modos de vida, teve na tecnologia um de seus artífices e, no decorrer do vindouro século XX, essa tendência só se aprofundou. As pioneiras peças de publicidade de eletrodomésticos, em sua pedagogia voltada às donas de casa de classe média, ilustram a força dos valores do que era considerado um lar "moderno". Por outro lado, desenvolveu-se também uma sensibilidade antagônica e complementar a esta, constituída pela valorização da tradição - reflexo, talvez, do desejo por rotinas e hábitos num mundo revolucionado por inovações e mudanças constantes. Um processo tão intenso que, como observou Eric Hobsbawm (1984), mesmo onde não havia tradições elas trataram de ser inventadas. Talvez resida aí uma das raízes da atual nostalgia precoce e da voga da memória.

Para o sociólogo Frank Furedi, estudioso da cultura contemporânea, uma de suas características seria a nostalgia precoce, promovida como algo cool, materializada no consumo de brinquedos, souvenirs de séries televisivas antigas, desenhos animados, jogos eletrônicos, artigos de papelaria e escritório de marcas "infantis" como Hello Kitty, Garfield, Snoopy, etc. (FUREDI, 2004). A velocidade e a facilidade de comunicação das novas tecnologias, em especial da Internet, tendem a marcar a rapidez cada vez maior do fluxo temporal, ampliando a sensação de obsolescência. É como se o tempo vivido se tornasse diferente do tempo medido. Em vários sentidos, esse processo de nostalgia precoce é correlato dos processos de desencaixe da modernidade tardia (GIDDENS, 1991), de desengajamento e perda de referenciais sólidos da modernidade líquida (BAUMAN, 2001).

Essa busca pela memória, pelo autêntico, se traduz muitas vezes, como observam Lipovetsky \& Serroy (2015, p. 407), numa “busca das 'raízes', da celebração das regiões, da proliferação dos museus e ecomuseus. É o culto do patrimônio, com seus bairros reabilitados, a fachada de seus imóveis restaurada, os galpões reconvertidos. É também a moda do vintage". Concorrem aqui, obviamente, determinações de outra natureza, como os interesses dos governos e das corporações, da indústria do turismo, dos movimentos sociais, etc. Mas o importante é perceber que, 
Marco Antônio de Almeida ${ }^{1}$

Giulia Crippa ${ }^{2}$

independentemente disso, esse processo incorporou-se ao senso comum, no sentido de proporcionar um horizonte motivador e explicativo para as ações dos indivíduos e grupos.

Nosso objetivo, neste texto, não é aprofundar a gênese ou a consequência desse processo, mas, a partir de uma cartografia exploratória, investigar algumas experiências capazes de permitir reflexões e problematizações acerca das relações que contemporaneamente estabelecem-se entre memórias, patrimônios e tecnologias. Nosso ponto de partida apoia-se numa hipótese, a de que esse processo opera numa dialética entre dois polos: de um lado, uma certa recusa ou reticência diante da tecnologia em prol de uma experiência/recuperação autêntica da tradição; de outro lado, a perspectiva do uso da tecnologia como possibilidade de recuperação/preservação do passado. Trata-se, obviamente, de uma oposição "ideal", nos termos weberianos - sabemos da inexistência de tais extremos na realidade empírica. Apesar disso, tal oposição nos é útil para localizarmos num continuum as experiências que iremos analisar e nos apercebermos de suas ambiguidades.

\section{A casa burguesa como lugar de memória: etnografia para a conciliação.}

As lembranças e as memórias são sujeitas à mudança, não mais mantidas unidas em narrativas coerentes, no horizonte contemporâneo, por alguma voz de autoridade (o Rei, o Estado...), capaz de desvelar, dessas memórias, um sentido "exemplar". Os lugares de memória encenam a narrativa dos poderes (temporais e espirituais) - materializados nas pedras de palácios, castelos, templos e igrejas, bem como nas representações do trabalho e do lazer - se toda época representa suas batalhas, suas vitórias, seus anseios e seus medos, o faz a partir de lugares e objetos que elege como representativos, para que se tenha memória disso. Nesse sentido, a memória que estamos buscando produzir pertence a uma dialética que continua as antigas narrativas sobre o poder, a riqueza, o trabalho, o descanso, os indivíduos, as coletividades. Resta perguntar: quem se tornou protagonista dessa narrativa e com que meios conta sua própria história?

Um dos âmbitos que pode ser enfocados é o das memórias criadas em espaços privados, em busca de suas dimensões cotidianas, de sua progressiva sedimentação em hábitos e gestos que falam de passados em que não é mais a unicidade a constituir o modelo, mas o reconhecimento, a adesão dos públicos nos aspectos domésticos da vida.

A memória de como morar, de como se reside, é observável quando a arqueologia busca, como indicador do "humano", a construção de um espaço e de um tempo domesticados. Os estudiosos da pré-história apontam, na origem da cultura, o estabelecimento de um "perímetro de segurança", de um "refúgio fechado", isso é: um espaço escolhido como habitat específico, que 
responde à necessidade de ordem, contraposto ao caos e a violência externos da sobrevivência na natureza hostil ou na guerra. (LEROYGOUHRAN, 1977)

A construção de uma "barreira" é só um isolamento aparente, que não impede que os elementos do universo externo penetrem, tanto materialmente como simbolicamente. Desde seu aparecimento, a moradia é um princípio de ordem que permite ao homem interpretar os dados da realidade em volta. Nenhuma surpresa, portanto, em nosso interesse etnológico pelas "casas" de populações distantes no tempo e no espaço, bem como na preservação e manutenção das antigas residências. A memória, entrelaçando o público e o privado, o indivíduo e seu grupo e, no panorama das últimas décadas, o interesse memorial $\mathrm{e}$ patrimonialista, vem construindo um espaço inédito: o da residência burguesa, que redesenha as fronteiras entre o indivíduo e a coletividade, entre as sombras domésticas da antiga Óikos e as luzes da Pólis. Crucial, a casa parece destacar-se como lugar entre os lugares, propondo-se a constituição de uma relação simbólica entre espaços, tempos e emoções. As residências, sejam elas de qualquer época ou lugar, trazem de volta estratificações de vida no tempo sobre as quais a memória trabalha, incorporando na lembrança ou isolando no esquecimento áreas inteiras do passado.

É preciso pensar aqui a relação que se estabelece hoje com a casa, sentida como uma fortaleza capaz de contrastar uma certa crise contemporânea da experiência dos lugares de memória. Ela, com efeito, é um hiper-lugar, pois se coloca no cruzamento entre o passado e o presente, na medida em que a "moradia", e as formas de nelas vivermos são um lugar comum à humanidade. É, também, o lugar suspenso entre os espaços interiores e as superfícies abertas para os espaços externos: quartos mais íntimos opostos a aberturas portas, janelas, terraços - onde trocas e relações se estabelecem. No presente, em formas distintas do passado, a casa oferece o símbolo de geografias da segurança, o espaço feliz delimitado pelo perímetro doméstico se propõe cada vez mais a ser a certeza da existência, ao contrario do externo, que se contrapõe como indiferente e hostil.

Levada por essas percepções, a memória busca na casa a memória da vida em seus traços essenciais, tornando-a um laboratório em que o ciclo da existência se renova cotidianamente. É na casa que se satisfazem desde as necessidades primárias do corpo - alimentação, descanso, práticas de manutenção dos rituais de limpeza - bem como de lazer e conforto - desde a leitura de um livro em uma poltrona, ou a escuta do rádio, até o olhar que se apóia em uma fotografia numa prateleira, ou à recepção de pessoas em seus locais.

Na medida em que os interesses sociais e culturais dirigem suas atenções às formas de se morar, o que se observa hoje é o estabelecimento de lugares de memória que buscam moldar a idéia de "casa das casas", em que se alternam as representações de ocultação e exibição do que, antes, era privado: a encenação da memória domestica estimula a capacidade de reconhecer as práticas 
Marco Antônio de Almeida ${ }^{1}$

Giulia Crippa ${ }^{2}$

e a distancia e proximidade com nosso quotidiano, pois nossa vida se deposita em gestos e objetos que nesses novos monumentos reencontramos. Os objetos de uma casa são parte de nós, nos refletem: é o medo do que mexe com as cortinas, bem como a exposição das louças e talheres melhores. As casas oferecem, assim, "imagens agentes" desse universo doméstico, traduzindo-se em histórias, contos, relatos: móveis, bibelôs, pequenos utensílios compõem uma linguagem figurativa de uma retórica da intimidade, confundindo memória e olhar.

Como explica Bodei (2009), aparentemente, a idéia de casa é oposta à de museu, pois a primeira é o lugar do individual e a segunda do patrimônio coletivo de objetos dos quais foram apagadas todos os vestígios de funções e uso anteriores ao ingresso deles no museu, que os subordinou ao seu valor de exposição. Se tornam museus as casas das pessoas que uma dada sociedade ou cultura reconhece ilustres, destacadas pelo que realizaram ou pelas experiências vividas. Nessas moradias se busca realizar o desejo de manter inalterado o espaço que viveram e marcaram, tanto por questões de culto aos objetos que, por contato, adquiriram traços de suas personalidades, tanto para poder admirar seu poder ou riqueza. Hoje, essas formas de culto envolvem os objetos e as residências que pertenceram a políticos, personalidades do espetáculo, empresários de sucesso. Com freqüência, as casas-museus possuem a dupla função de lembrar o dia-a-dia e as qualidades das experiências vividas expondo objetos e obras com que a pessoa amava se cercar. Dentre as casas-museus há nuances que se vão desde a casa esvaziada dos objetos cotidianos até a habitação que revela o impulso humano de colecionar ou, simplesmente, reunir objetos que permitem tornar mais confortável e menos árida a vida, expressar gostos e comunicá-los.

Em uma casa-museu, a narrativa da memória se realiza pelos objetos mais comuns, herdados ou recebidos de presente, selecionados com cuidado, considerados preciosos por seus moradores, e o entrelaçamento de nossa experiência com os objetos que nos cercam permite o estabelecimento de relações com essa tipologia de museu que, não por acaso, tem se tornado relevante nos últimos anos.

Um velho talher ou uma cadeira "contam" a epopéia do minúsculo de uma história cotidiana etnologizada, isso é, na perspectiva de

observar e descrever o não exótico a partir de um olhar habituado ao exótico. [...] o objeto está desde já destinado a ser fruto do discurso que o põe em cena graças à "escritura etnográfica". [...] Praticar a "inquietante estranheza" em que tudo nos parece tão familiar. Em suma: apresentar a perspectiva de um olhar que faz surgir o enigma do que nós acreditamos conhecer muito bem. (JEUDY, 2005, p. 35)

É aos fragmentos de um passado comum próximo, contíguo, que emprestamos com facilidade maior algo de nós e, através das 
Marco Antônio de Almeida ${ }^{1}$ Giulia Crippa ${ }^{2}$

figuras de uma narrativa de "todos os dias" dentro do raio do reconhecimento da experiência compartilhada, a memória penetra nossas visões. Quer se trate da residência burguesa de uma "família de sucesso" do interior paulista ou da preservação dos cenários cinematográficos das casas dos Hobbits, transformadas em hotel temático na Nova Zelândia, o olhar etnográfico nos tranqüiliza: a casa não é uma fonte de rupturas, apesar de extravagante ou fantasiosa, ela sobrevive em suas raízes. Na medida em que "a ameaça de destruição dos marcos simbólicos das sociedades modernas não para de aumentar, sob a pressão das tecnologias da informação e da comunicação [...] a conservação patrimonial impõese, pois, como a via real de proteção do simbólico”. (JEUDY, 2005, p. 36)

A casa, portanto, é mediadora formidável da memória porque une a esfera da lembrança com a esfera da experiência, permitindo justificar o esforço de conservar para apostar em sua transmissão memorial para o futuro.

Um exemplo para a reflexão sobre atuar em uma casa que se torna museu pode se observar no Instituto Casa da Memória Italiana, uma fundação particular sem fins lucrativos que busca promover e preservar a história da imigração italiana na região do oeste paulista, realizando atividades no espaço da casa histórica, que se torna museu, construída no centro da cidade de Ribeirão Preto nos primeiros anos do séc.XX. Residência da família de Pedro e Eugenia Biagi, por mais de sessenta anos, sua construção não é resultado da vontade e do gosto da família, pois tratava-se, originalmente, da residência urbana de D. Joaquina Evarista Meirelles, fazendeira de café de origem portuguesa, e de seus filhos. Observa-se, nessa passagem da propriedade, a transição entre os antigos donos do café e os novos donos da cana-de-açúcar, a qual a fortuna da família Biagi é ligada. Desde a afirmativa sobre a transformação econômica da região, é claro que se estabelece uma relação entre o sucesso da família nos negócios e a casa: ela se torna referência para a transformação familiar, materializando uma memória positiva. Apesar de em sua origem ser a casa de uma abastada família portuguesa, como "lugar de memória" vincula-se de maneira clara às memórias ligadas à imigração italiana da família que começa nesse lugar - onde o que é declarado é o modelo do sucesso no tempo. O Instituto Paulista de Cidades Criativas e Identidades Culturais (IPCCIC), responsável pela idealização e cuidados do Instituto Casa da Memória italiana, assim esboça o projeto sobre ele: 
dar visibilidade ao trabalho do Instituto Casa da Memória Italiana e garantir a visita virtual ao prédio histórico, sede da entidade. (http://www.ipccic.com/\#!italiana/c1m9t)

A Casa da Memória Italiana se constitui como espaço institucional de memória enquanto estrutura arquitetônica, pelas pinturas decorativas e pelo mobiliário original da década de 1920. Ainda, a Casa possui a memória instituída por uma coleção de fotografias da família Biagi e objetos de uso pessoal e doméstico. Os estudos sobre o mobiliário, de natureza mais histórica, se revelam em sua sinergia com interesses mais antropológicos e sociais, em que se destacam as memórias costuradas pelos relatos dos costumes culturais de festas e de hábitos cotidianos ligados aos fazeres da culinária italiana, que os representantes da família lembram em relação à nonna.

O projeto da Casa da Memória Italiana se propõe a produzir suas experiências em ambientes valendo-se dos recursos oferecidos pelas tecnologias digitais. Sua proposta não é somente divulgar sua memória material, mas produzir outros recursos de memória realizando entrevistas em vídeo com as famílias descendentes dos imigrantes italianos, produzindo, assim, um acervo que pode ser disponibilizado em rede.

Mesmo que o projeto do Museu se proponha ao estabelecimento de um diálogo com a população de Ribeirão Preto e região, propondo ações que possibilitem socializar as informações sobre a memória italiana, resulta claro que a narrativa de memória a ser destacada privilegia o confronto cultural com o cotidiano bem sucedido e saudoso que a etnografia compõe, no lugar de um confronto histórico que represente conflitos na produção da riqueza e valores que a casa "representa". Nesse sentido, as ferramentas tecnológicas utilizadas amplificam, selecionando as memórias que se propõe a gravar - aquelas de sucesso - e disseminando-as em rede. Dessa maneira, a memória de um passado aparentemente próximo de todos os visitantes (a casa, seus objetos, o cotidiano de seus moradores), estabelece uma ordem do discurso que estabelece uma visão positiva que privilegia a descrição de uma ordem domestica sobre os conflitos sociais dentro da visão dos protagonistas exemplares que nelas viveram. Por sua vez as tecnologias amplificam e disseminam globalmente tal ordem que, institucionalizada dentro de um website, se torna legítima e legitimadora. De maneira funcional, a tecnologia se articula com o espaço privado que se torna coletivo para fortalecer visões de mundo, princípios de organização social.

$\mathrm{Na}$ mesma região que o museu anteriormente comentado, o Museu Casa de Portinari, em Brodowski, localiza-se na antiga residência do conhecido artista plástico. O perfil da instituição constitui sua identidade institucional a partir da ligação do artista com sua terra natal, origens e laços familiares. É o local onde ele realizou suas experiências com pinturas murais e se aprofundou na técnica com o passar dos anos. Devido às várias obras em pintura 
mural nas paredes da casa e em uma capela nos jardins da residência, tornaram-se prioritárias ações para a preservação do conjunto. Em dezembro de 1968 a casa foi tombada pelo IPHAN (Instituto do Patrimônio Histórico e Artístico Nacional) e, no ano seguinte, o imóvel foi desapropriado e adquirido pelo governo do Estado de São Paulo. Em janeiro de 1970 foi finalmente tombado pelo CONDEPHAAT (Conselho de Defesa do Patrimônio Histórico, Arqueológico, Artístico e Turístico do Estado de São Paulo) e o museu foi instalado e inaugurado em março do mesmo ano. O complexo é constituído por uma casa principal, e anexos construídos em sucessivas ampliações.

O museu procura manter uma "simplicidade típica do interior como sua maior característica", segundo o website do museu. Por outro lado, não descurou do uso de algumas tecnologias, agregando-as ao patrimônio do museu. Nesse sentido, desenvolve o projeto "Juntando Memórias", voltado ao registro da memória local, coletando e identificando fotografias e vídeos que foram registrados em eventos públicos realizados pelo próprio museu, exibidos em seu website. $\mathrm{O}$ vínculo com a memória da colonização italiana na região é bastante marcado: durante a programação da Semana de Portinari também acontece a "Piazza Della Nonna", festa típica inspirada na cultura dos primeiros imigrantes que se estabeleceram na cidade. $\mathrm{O}$ evento conta com gastronomia, música e homenagem às famílias tradicionais, e as barracas de comidas típicas são comandadas por associações filantrópicas da própria cidade. Outra apropriação da tecnologia, disponível no website, intitula-se "Poéticas de Memórias", contemplando nove vídeo-depoimentos de pessoas da comunidade, em sua maioria idosos, estabelecendo através de suas reminiscências o laços identitários construídos em torno do imaginário acerca do artista e de sua residência.

No caso do Museu Casa de Portinari, a apropriação da tecnologia é discreta, servindo muito mais como apoio à reconstrução identitária/memorialística da comunidade, tomando o museu como eixo de atração em torno do qual se articulam ainda hoje as ações culturais presenciais e ritualísticas que renovam experiência dos moradores locais. Na verdade, é possível perceber que o papel do museu não se restringe a salvaguardar um patrimônio artístico-cultural "tombado", mas também constituir-se como um centro de irradiação de processos de manutenção e reforço de uma identidade local articulada aos eixos da imigração italiana e da presença histórica do artista Cândido Portinari. Assim, acaba por incidir na dinâmica socioeconômica do município, fomentando atividades ligadas ao turismo.

\section{A memória em artefatos e bytes: usos institucionais e não-institucionais das tecnologias}

Outra problemática advém dos museus e instituições que investem fortemente nas tecnologias como processos e ferramentas na construção de um patrimônio, estabelecendo assim ligações com 


\section{Marco Antônio de Almeida ${ }^{1}$}

Giulia Crippa ${ }^{2}$

1 Historicamente, a Era Meiji corresponde ao período $1868-1912$, mas as edificações e instalações do museu cobrem um período um pouco mais alargado de tempo. As citações a seguir, sobre o museu, sempre que não referidas, são do site:

https://www.meijimura.com/english labout/index.html o passado que agregam mais camadas de mediação e, por conseguinte, de complexidade.

No Japão, em 1965, foi inaugurado o museu Meiji-Mura, a uma hora de distancia de Kyoto e de Osaka. Trata-se de um museu dedicado ao período em que no Japão tudo se tornava europeu - a era Meiji ${ }^{1}$ : bondes, trens, iluminação urbana, conhecimento científico e tecnológico, indústria, moda e postura aparentemente tornavam o Japão um pais totalmente ocidentalizado. Não se trata do mesmo fenômeno ligado ao gosto exótico da "japoneserie", que apontava e comunicava as diferenças, febre estética de consumo que tomou conta da Europa quando da abertura dos portos japoneses ao comércio internacional. Para o Japão foi a busca de um poder científico e tecnológico capaz de competir com o Ocidente, e não de uma aceitação passiva de uma supremacia tecnológica. Para o Japão, o Ocidente não se reduzia à mera transfiguração de suas figurações, mas se tornou necessidade vital para o país competir no panorama internacional, assumindo os traços ocidentais quando necessário. O museu Meiji-Mura foi criado para documentar, de maneira sintética, esse fenômeno de modernização científica e tecnológica. Trata-se de um parque temático, no espaço do qual foram transportados e reconstruídos 67 prédios históricos provenientes de todas as regiões do Japão desse período.

O vilarejo, em tamanho natural, oferece aos visitantes serviços de transporte em bondes, trens e carros de época. Alguns dos prédios, como o Imperial Hotel de Frank Lloyd Wright, construído em 1923 em Tokyo, é uma reconstrução na base de documentos, pois o original foi demolido em 1965.

$\mathrm{Na}$ prática, trata-se de uma cidade virtual do passado modernizador, pois cada edificação, separada e afastada de seu contexto histórico e geográfico, constitui um espaço museológico específico. Em cada prédio há exposições temáticas, permanentes e temporárias, como se configurassem pequenos museus temáticos da Era Meiji, como anunciado pelo site, "On display inside the buildings are furniture and other items of interest, objects of reference related to the respective buildings, and temporary exhibitions of historic materials as occasions call".

É interessante destacar que o cerne da discussão do museu é de natureza tecnológica, pois é a constante comparação entre a tradição japonesa e as técnicas e materiais ocidentais o que constitui a narrativa do museu, que destaca a adoção de "styles, techniques and materials of Western style stone and brick achitecture. With the progress of industrial revolution, these adoptions paved the way to modern architecture of steel, concrete and glass". Além disso, em 1965 a tecnologia se torna (re) produção que estrutura a própria visita ao museu. Com efeito, pela amplidão da área do parque, precisava de uma infraestrutura de transporte ferroviário e de bonde, sobre a qual rodar os comboios da época. Tudo isso, molda o ponto de vista da comunicação cultural, estrutura e temática histórica, que se orienta para um turismo nacional, pois o museu procura proporcionar 


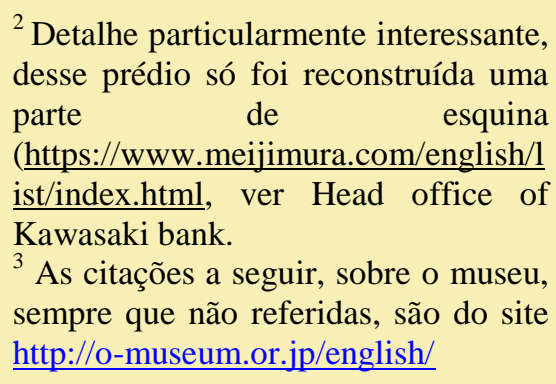

As citações a seguir, sobre o museu, sempre que não referidas, são do site http://o-museum.or.jp/english/

\begin{abstract}
Japanese people a place of social education, where they can discover and have first-hand contact with the form and spirit of the Meiji period. We also believe that the Meiji-mura, as an evidence of East-West cultural exchange, can be helpful to enhance mutual understanding between the peoples of Japan and other countries of the world.
\end{abstract}

Vale a pena destacar que o website do museu apresenta, além das versões em inglês e japonês, versões para um público chinês e coreano. Deixamos como hipótese a ser cogitada que há, nisso, uma questão histórica: com o desenvolvimento tecnológico da era Meiji, o Japão se tornou a potência imperialista capaz de subjugar tanto a China como a Coréia - o que potencializaria seu interesse para o turismo regional sul-asiático.

Dentre as edificações presentes na lista do site destacamos a presença de itens provenientes das áreas de emigração japonesa, como a casa do imigrante japonês, originariamente construída em Registro (SP), em 1919, em que a legenda da imagem a disposição diz que, apesar de ser construída com madeira local, carpinteiros e métodos japoneses foram utilizados. Da mesma maneira, as imagens legendadas dos prédios japoneses reconstruídos no museu é bem visível essa dialética de técnicas e materiais japoneses e ocidentais. Uns exemplos: a barbearia "Kinotoko", construída como loja de dois andares em estilo Edo tradicional, foi transformada em barbearia fahion, quase em estilo ocidental; o quartel militar da Infantaria se baseia em um projeto de um livro de arquitetura
Frances e foi construído "by learning from foreign examples"; o escritório central do Banco Kawasaki é em estilo renascentista, destacando na legenda sua estrutura em concreto armado $^{2}$; o escritório e alguns quartos do hospital Nagoya Garrison Hospital, que na legenda é definida como design típico para grandes hospitais Ocidentais (ver, no website, Ward and Administraiton Office, Nagoya Garrison Hospital).

A edificação da prisão de Kanazawa oferece uma perspectiva peculiar à discussão sobre tecnologias, na medida em que a estrutura reconstruída oferece um modelo carcerário de Panoptikon: "Five wards are arranged radially around the octagonal central guard office." (ver, no website, Central Guard Station and Ward, Kanazawa Prison).

Observa-se, nesse museu, em que medida a tecnologia desempenha um papel de destaque,estrutural quanto na orientação do discurso memorial. Por esse exemplo, de 1965, não é de hoje o investimento nela para "incrementar" o interesse dos públicos visitantes.

Ainda no Japão encontra-se outro museu que encena a memória através da tecnologia como ferramenta e como representação. Trata-se do Museu de Arte de Otsuka ${ }^{3}$, localizado em Naruto, estabelecido para comemorar os 75 anos de atividade do ramo farmacêutico da empresa Otsuka. Mais um museu que surge e abre suas portas aos públicos com base na vontade de atores privados. O museu de Otsuka se apresenta como museu de arte mas, 


\section{Marco Antônio de Almeida ${ }^{1}$} Giulia Crippa ${ }^{2}$

na verdade, o termo é utilizado de maneira muito ambígua pelo site: com efeito, se trata de um museu dedicado à "arte" entendida como fabricação de cerâmicas, "The Otsuka Museum of Art is a "Ceramic board masterpiece art museum". As cerâmicas expostas representam acerca de mil obras selecionadas por um comitê de seis historiadores da arte entre aquelas consideradas "universais", que pertencem ao Ocidente desde a Grécia antiga até a arte contemporânea.

Reproduções, portanto, realizadas através de uma sofisticada tecnologia industrial, que permitem aos visitantes vivenciar a experiência dessas "obras primas" em tamanho e cores naturais, "These masterpieces are reproduced to their original size using special techniques by the Otsuka Ohmi Ceramics Co., Ltd. Unlike the paintings in art books or textbooks, visitors will able to appreciate the true artistic value of the original works, and experience art museums of the world while being in Japan.”.

A reprodução tecnologicamente sofisticada das obras, explicada através da história do papel desempenhado por esse setor das indústrias Otsuka na indústria nacional, leva a uma visão paradoxal da memória conservada no museu: convida explicitamente à inversão na apreciação das obras (primeira, se vê a cópia, depois o original, que lembrará da cópia vista no passado)

We will certainly feel very happy if our visitors, having contemplated the images exhibited at our museum, may someday decide, on the occasion of their honeymoon, to travel overseas to see the original picture. They would then remember that they had already seen this or that image at our museum, when they were students, and that they then felt impressed by it. (http://omuseum.or.jp/english/publics/index/18/)

Ainda, oferece uma visão de tecnologia como única garantia de eternidade das obras (ou melhor, de suas copias). O museu, de fato, se propõe a ser o "cofre" dessas obras, resistente a terremotos, explosões, tsunamis, enfim, às catástrofes que podem destruir as obras originais. A copia perfeita, depósito da idéia original que a tecnologia produz resistirá, sempre graças à tecnologia, realizando o sonho de imortalidade que todo museu deseja.

Estes são casos de patrimônios materiais que incorporam a tecnologia (ou que se constituem a partir da mesma, como o Museu Otzuka) enquanto mecanismo de recuperação de uma "aura" nostálgica perdida no passado. Iniciativa um pouco diferente é a dos aparatos informacionais que buscam recuperar os traços de um "patrimônio imaterial" distinto daquele definido por órgãos como a UNESCO ou o IPHAN, mas testemunhos de rituais de consumo de produtos culturais produzidos industrialmente. $\mathrm{O}$ site da editora de histórias em quadrinhos EBAL, por exemplo, conecta-se a uma rede de aficionados que ampliam as fronteiras dessas memórias por eles vividas em seus blogs e grupos de discussão voltados a esse universo.

A Editora Brasil-América, mais conhecida por seu EBAL, foi uma das mais importantes editoras de história em quadrinhos do 
Brasil. Fundada 1945 por Adolfo Aizen, foi de extrema importância na difusão do gênero no país. Manteve suas atividades por 50 anos, fechando em 1995. Possui algumas fanpages no Facebook (sendo considerada a página "oficial” https://www.facebook.com/EBAL.editora/timeline?ref=page_intern al) e um website na internet, (http://guiaebal.com/), com informações acerca de todas as HQs lançadas pela editora desde a sua fundação até seu encerramento, com as datas corretas e numero de edições por séries, para colecionadores, professores, admiradores e curiosos. Em seu acervo digital constam 10.030 capas de publicações escaneadas, bem como 4.418 histórias em quadrinhos completas (o equivalente a $44 \%$ do acervo da EBAL).

O que o torna interessante é que se trata, principalmente, de um empreendimento coletivo dos aficcionados. No próprio website os internautas que o visitam são encorajados a colaborar com o mesmo, enviando cópias digitalizadas de suas revistas. Desse modo, o site em conexão com as fanpages estabelece um circuito de trocas assentado numa lógica de "economia da dádiva”, típica da cultura da convergência descrita por Jenkins (2009). Os aficcionados agregam comentários, informações históricas sobre as publicações e reminiscências sobre o consumo cultural das mesmas. Também funciona como ligação para um mercado de nicho de colecionadores de revistas antigas.

O Museu das Coisas Banais (https://www.instagram.com/museudascoisasbanais/ ) é um museu virtual que existe apenas na internet, e foi constituído inicialmente como um projeto de pesquisa vinculado ao Instituto de Ciências Humanas da Universidade Federal de Pelotas (UFPEL). Criado em 2014, está voltado para a preservação e o compartilhamento das memórias pessoais e para a reflexão sobre a cultura material do tempo presente, valorizando a relação dos homens com os objetos e as diferentes formas de vinculação entre memória e materialidade. As informações coletadas e/ou relativas ao MCB (incluindo fotografias, narrativas, dados dos doadores, origem e estado de preservação dos objetos) assim como dados referentes aos acessos (número de visitantes, localização dos visitantes e, no caso do Facebook/Instagram, de "curtidas" e de "compartilhamentos") são digitalizados e salvaguardados em HDs externos.

Segundo os envolvidos no projeto, a proposta articula-se a partir das discussões acerca dos objetos como portadores de memória, em particular aqueles presentes no cotidiano, as ditas coisas banais, presentes no dia-a-dia, frequentemente como objetos biográficos, mas em geral ausentes nos museus. Desse modo, um dos objetivos que a sua pesquisa busca alcançar por intermédio do MCB é discutir o estatuto desses objetos como objetos museológicos. Para eles, o valor documental da fotografia, associado ao da narrativa que envolve os objetos que compõem o acervo do museu se configuram como elementos do patrimônio cuja dinâmica de visitação/acesso proporcionada pela rede reconfigurou, dessacralizando-os enquanto objetos museais. Desse modo, passam 


\section{Marco Antônio de Almeida ${ }^{1}$}

Giulia Crippa ${ }^{2}$

a considerar preservável todo objeto que apresente um valor afetivo capaz de evocar memórias vinculadas à identidade do seu doador. (BEZERRA; SERRES; CHAVES, 2015) Além disso, o MCB proporciona uma problematização da própria dimensão de temporalidade relacionada à memória: os jovens, principalmente, registram e compartilham sua memória cotidiana através de fotos e textos no momento mesmo dos acontecimentos. Essa "memória imediata" é compartilhada e torna-se acessível a qualquer um de seu próprio círculo de amizades. Viveríamos um eterno tempo presente, onde a memória se fundiria ao instante?

Nesse sentido, caberia perguntar em que medida esses aparatos, como os sites da EBAL e do MCB, assim como os processos que desencadeiam, não seriam ainda mais "eficazes" na tentativa de recuperar as experiências vividas, "objetivando-as" no compartilhamento não só dos bens culturais digitalizados, mas também nas memórias e reminiscências.

\section{Considerações finais}

Uma leitura possível do conceito de aura implica em não conectá-lo diretamente aos valores artísticos ou culturais enquanto tal, mas às dificuldades de se ter acesso ao bem ou objeto original. Por esta via, entramos na lógica de mercado que atribui valor aos bens escassos ou de maior raridade - os custos e dificuldades no acesso é o que constituem performativamente o valor e atribuem a aura a estes bens ou objetos. Nesse sentido, a ideia de vulgarização não traria em si, inicialmente, a definição de objetos carentes de qualidade (estética e/ou cultural), mas de objetos e bens que estariam acessíveis ao "vulgo", à maioria.

$\mathrm{O}$ entendimento do processo de vulgarização desliza posteriormente para uma conotação de juízo, de desvalorização, na medida em que a ampliação do acesso ameaça romper os mecanismos de distinção (BOURDIEU, 1989). Talvez esteja aí uma das chaves para se compreender as dificuldades e estranhezas que cercaram a recepção inicial do texto de Benjamin. De forma semelhante, a emergência das tecnologias digitais nos últimos anos repõe os problemas levantados por "A obra de arte na época de sua reprodutibilidade técnica".

Em alguns dos exemplos assinalados, foi possível perceber o uso da tecnologia como busca de recuperar a experiência do momento e re-inserir o objeto em seu fluxo de tempo original. Trata-se, poder-se-ia dizer, de uma tentativa de reconstituir ou devolver a aura aos objetos, como se pode observar no Museu Meiji. No caso do Museu Otzuka, em sua supervalorização da tecnologia como garantia de preservação do patrimônio artístico da humanidade, temos um passo além, a construção de uma espécie de "trans-aura" - uma cópia "mais perfeita", ou tecnologicamente mais "garantida" que o próprio original. 
No caso dos sites como o da EBAL e do MCB, o recurso às redes sociais reconstrói uma aura que não está nos objetos em si (embora essa dimensão ainda esteja presente em certos aspectos relacionados ao colecionismo), mas principalmente numa comunidade construída em torno da nostalgia, nas reminiscências de consumos culturais compartilhados.

Nostalgia e autenticidade reinventam-se enquanto categorias que, mais do que determinar valores, configuram práticas culturais que se modificam pela incorporação de aparatos tecnológicos, deslocando os circuitos de legitimação simbólica e abrindo a possibilidade de constituição de novos "patrimônios".

Voltando ao ensaio de Benjamin, um dos eixos do trabalho articula-se na discussão quantidade-qualidade. Para ele, ao ultrapassar-se certos patamares de consumos culturais e comunicativos, a quantidade se converteria em outra espécie de qualidade. Tese polêmica e bastante discutível, mas que aponta, de qualquer modo, para uma mutação nas estruturas perceptivas - a concentração e o "choque" abrindo espaço para uma percepção mais difusa e múltipla tecida na distração.

Com a desaparição da aura não está em questão apenas a perda do valor da arte e da cultura em geral, mas a emergência de outro tipo de valor, de natureza distinta, mais político e comunicativo (o quê, no ensaio, é tratado por Benjamin como a passagem do "valor artístico" ao "valor de exposição"). Aqui, retomando os mecanismos de distinção de Bourdieu, toda avaliação tende a considerar os valores anteriores como mais "autênticos", e a acessibilidade contemporânea - a vulgarização - como um processo de geração de conteúdos de "pior" qualidade e de duvidoso valor cultural.

Por meio dos exemplos analisados, retornamos à nossa hipótese inicial, que envolvia a oposição de dois polos: o da recusa ou reticência diante da tecnologia em prol de uma experiência/recuperação autêntica da tradição; de outro lado, a perspectiva do uso da tecnologia como possibilidade de recuperação/preservação do passado. Os exemplos analisados ou mencionados apontaram que, na realidade, a atitude das pessoas em geral e mesmo dos profissionais do patrimônio e da memória é, em realidade, bem mais ambivalente. Entre as ambiguidades percebidas, está o próprio status simbólico que as tecnologias adquirem contemporaneamente. Para além das relações que as tecnologias estabelecem com as concepções de memória, patrimônio ou tradição, está o fato de que a própria tecnologia, hoje, também passa por um processo que busca incorporar uma camada de nostalgia a alguns de seus artefatos. Passa por aí a moda vintage dos vinis (agora acrescida de um retorno às fitas-cassete), do mesmo modo que algumas releituras musicais (gravações com instrumentos de época) ou literárias (a voga steampunk, por exemplo). Aparentemente, isto parece relacionar-se com as consequências de um processo de socialização cada vez mais imbrincado com as tecnologias de informação e comunicação. 
Assim, em relação aos patrimônios e às memórias, passam a valer, com a disseminação possibilitada pelas tecnologias digitais, novas regras e procedimentos que, no mínimo, reconfiguram ou mesmo colocam em xeque as antigas noções de curadoria. Em movimento análogo ao descrito por Benjamin, em que cada indivíduo podia postular o direito democrático de ser filmado, hoje, no limite, cada indivíduo pode postular o direito de ser o curador de suas memórias e convertê-las em patrimônio, como demonstra a experiência do MCB e outras similares.

Nesse aspecto, em que pesem as diferenças de momento histórico e de faixa etária, podemos recordar o amnésico protagonista de A misteriosa chama da rainha Loana (2005), de Umberto Eco, que só consegue recuperar sua memória pessoal por meio da revisitação de sua coleção juvenil de quadrinhos, livros e LPs - marcos de uma geração que viveu, pela primeira vez, o impacto da cultura de massa. Nesse sentido, estaríamos vivendo um movimento paradoxalmente inverso ao diagnosticado por Benjamin em relação à perda da aura? Assim, se como afirma Donna Haraway (2009), somos todos cyborgs, que destino mais previsível que o de relacionarmos nossas memórias aos aparatos tecnológicos que nos cercam?

\section{Referências Bibliográficas}

BAUMAN, Zigmunt: Modernidade Líquida. Rio de Janeiro: Jorge Zahar, 2001.

BENJAMIN, Walter. A obra de arte na era de sua reprodutibilidade técnica. In: Obras Escolhidas vol. 1. São Paulo: Brasiliense, 1987, p. $165-196$.

BEZERRA, D. B.; SERRES, J. C. P.; CHAVES, R. T. Museu das Coisas Banais: Cultura material e virtualidade. Trabalho apresentado no VI Seminário Internacional de Políticas Culturais Rio de Janeiro: Fundação Casa de Rui Barbosa, 2015, p. 1-11.

BODEI, Remo. La vita delle cose. Bari: Laterza, 2009.

BORGES, Jorge Luis. Funes, o memorioso. In: Ficções. São Paulo: Companhia das Letras, 2007, p. 99-108.

BOURDIEU, Pierre. O Poder Simbólico. Rio de Janeiro: Bertrand Brasil, 1989.

CANCLINI, Néstor García. Diferentes, desiguais e desconectados mapas da interculturalidade. Rio de Janeiro: Editora UFRJ, 2005.

\section{EBAL Editora Brasil-América Limitada http://guiaebal.com}

ECO, Umberto. A Misteriosa Chama da Rainha Loana: romance ilustrado. Rio de Janeiro: Record, 2005.

FUREDI, Frank. Não quero ser grande. Folha de São Paulo. São Paulo, 25 jul. 2004. Mais!, p. 4-6.

GIDDENS, Anthony. As conseqüências da Modernidade. São Paulo: Editora da UNESP, 1991.

HARAWAY, Donna. Manifesto Ciborgue. In: SILVA, Tomaz Tadeu (org.) Antropologia do Ciborgue: as vertigens do póshumano. Belo Horizonte: Autêntica, 2009, p. 33-118. 
HOBSBAWM, Eric. A invenção das tradições. Rio de Janeiro: Paz e Terra, 1984.

JENKINS, Henry. Cultura da convergência. São Paulo: Aleph, 2009 ( $2^{\mathrm{a}}$ ed.)

JEUDY, Pierre. Espelho das cidades. Rio de Janeiro; Casa da Palavra, 2005

LEROY-GOUHRAN, André. Il Gesto e la Parola, II: la memoria e i ritmi. Torino: Einaudi, 1977. LESSIG, Lawrence. Cultura Livre. Disponível em:
http://softwarelivre.org/samadeu/lawrence-lessig-cultura-livre.pdf

LIPOVETSKY, G.; SERROY, J. A Estetização do Mundo: viver na era do capitalismo artista. São Paulo: Companhia das Letras, 2015.
MUSEU
CASA
$\mathrm{DE}$
PORTINARI

http://museucasadeportinari.org.br/

MUSEU DA IMIGRAÇÃO ITALIANA

http://www.ipccic.com/\#!italiana/c1m9t
MUSEU
DAS
COISAS
BANAIS

https://www.instagram.com/museudascoisasbanais

MUSEU DA ERA MEIJI

https://www.meijimura.com/english/about/index.html

MUSEU OTZUKA http://O-museum.or.jp/english 